\title{
Wireless sensor networks for extreme environments: remote sensing and space industry
}

\author{
Mohammed E. El-Telbany* \\ Department of Computers and Systems, \\ Electronics Research Institute, \\ Cairo, Egypt \\ Fax: +202-33369738 \\ Email: telbany@eri.sci.eg \\ *Corresponding author
}

\section{Maha A. Maged}

Department of Communications,

National Authority of Remote Sensing and Space Sciences,

Cairo, Egypt

Fax: +202-26225800

Email: maha_maged@narss.sci.eg

\begin{abstract}
The adoption of wireless sensor networks (WSNs) for environmental monitoring is currently considered one of the most challenging applications for this emerging technology. These set of sensors that collaboratively perform embedded sensing and communication tasks owned features such as low cost, flexibility, fault tolerance, high sensing fidelity, creating many new and exciting applications for remote sensing and space industry where many essential phenomena have hardly been investigated. In this paper, a state-of-art survey clearly shows the WSNs have been successfully implemented and tested in remote sensing applications. Morevever, the developments and challenges in design WSNs for space-based application are discussed in order boost the use of WSNs in remote sensing and space industry in Egypt.
\end{abstract}

Keywords: wireless sensor networks; WSNs; remote sensing; satellite; space industry.

Reference to this paper should be made as follows: El-Telbany, M.E. and Maged, M.A. (2019) 'Wireless sensor networks for extreme environments: remote sensing and space industry', Int. J. Hybrid Intelligence, Vol. 1, No. 1, pp.41-54.

Biographical notes: Mohammed E. El-Telbany received his $\mathrm{PhD}$ in Computer Engineering at the University of Cairo. He is an Associative Professor at the Department of Computers and Systems, Electronics Research Institute. His research interests include issues related to machine learning, robotics and embedded sensor systems. He is the author of a great deal of research studies published at national and international journals, conference proceedings as well as book chapters. 
Maha A. Maged received her MSc in Electronics and Communications Engineering at the Cairo University. She is an Engineer at the Department of Space Communications, National Authority of Remote Sensing and Space Science (NARSS), Egypt. Her research interests are related to WSNs, antennas and satellite communications. She has co-authored many research papers at international journals and conference proceedings.

This paper is a revised and expanded version of a paper entitled 'A review of wireless sensor applications in remote sensing and space industry' presented at International Conference on Advanced Intelligent Systems and Informatics 2017 (AISI 2017), Cairo, Egypt, 9-11 September 2017.

\section{Introduction}

The beginning of terrestrial WSNs era, many promising applications for earth environmental observation are growing. Terrestrial WSN is one of such technology which consists of a set of tiny distributed wireless nodes that have to collaborate and cooperate on a common distributed application to monitor or collect data from surrounding environment and pass the information with different resolution and accuracy to the base station or fusion centre (FC) for remote user access through various communication technologies (see Figure 1) (Akyildiz et al., 2002; Hill et al., 2002). The WSN currently is a solution for many practical problems in environment controlling. Obviously, WSN is deployed in many regions and used in remote and hazardous environments where many important phenomena have seriously been examined due to their inaccessibility. They have emerged as an alternative to remote sensing techniques which typically composed of a single or a few calibrated static sensors that acquire homogeneous streams of data in highly controlled environments. The terrestrial WSNs features such as low cost, flexibility, fault tolerance, high sensing fidelity, make them suitable for new and exciting applications in remote sensing for monitoring the physical world over long periods of time and across extended geographical areas. In contrast to traditional remote sensing techniques, in which data are obtained during overpass periods, monitoring by WSN is continuous and in real time and complements its data by providing ground trouthing for validation of satellite and aerial remote sensing ( $\mathrm{Li}$ et al., 2016; Mollenhauer et al., 2017). The collected samples may be used to reconstruct the interested physical phenomenon, referred as the signal or sensor field, in both time and space. The unmanned aerial vehicles (UAV) can be used as a mobile data collector in certain situations, e.g., sensor networks at difficult to reach areas (Mazayev et al., 2016; Trasvina-Moreno et al., 2017). These terrestrial WSNs currently have a large range of applications of sensor network has become integral part of our life and its research areas are active at several levels, starting from the component level, the system level and all the way up to the application level (Iyer et al., 2008). In recent years, many researches have explored the possibility of extending the use of WSNs from terrestrial applications to space applications (Barnhart et al., 2007). The development of space technologies, especially in satellite technology, suggests that space sensor networks which could provide a new capability to investigate widespread sensing phenomena. There are several opportunities in cooperation between constellation of small or pico satellites 
to monitor remotely interested regions. Such space sensor network expect increased mission flexibility and success by distributing the sensing tasks. Unlike terrestrial environment, the space is hazardous to satellites and spacecraft due to radiation, debris and the thinning atmosphere (Barnhart et al., 2007; Vladimirova et al., 2008; Barnhart, 2008). The application of space sensor networks has been utilised by applying advanced technology to space based on small and lightweight satellites with limited power and transmission capabilities at very low orbits.

Figure 1 The terrestrial WSN architecture (see online version for colours)

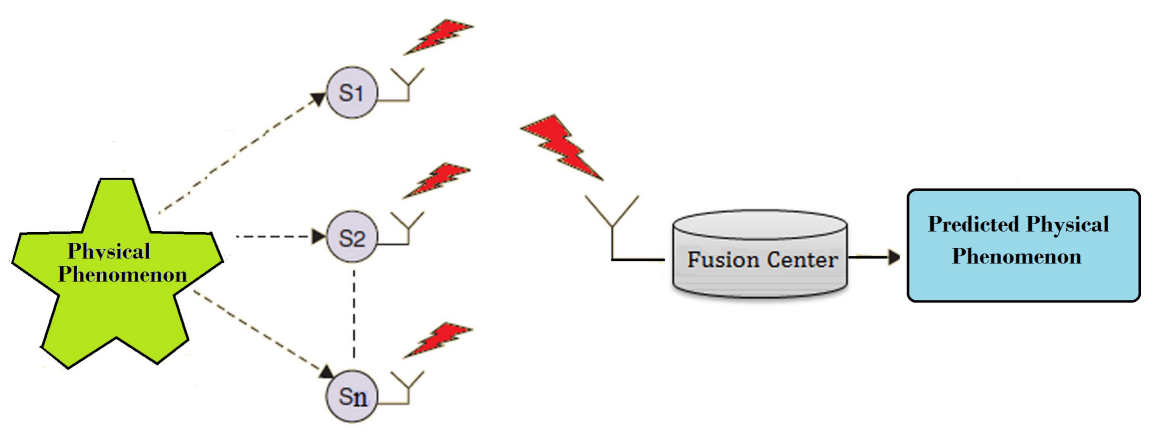

Note: Each sensor can make a decision and send it to the FC where decision fusion takes place.

The architecture of terrestrial WSN consists of collection of distributed sensor nodes, each node can sense, compute and communicate with each other. The sensors can detect events or changes from environment and provides corresponding data. The sensor node can either receives message or transmits message and can transmits messages to a gateway via self-configuration and multi-hop routing. The gateway can use many ways to communicate with remote network, such as internet and satellite and more than one gateway may be used for large-scale application. Due to its limited communication areas the node must use multi-hop routing to access the nodes out of communication areas. The sensor node comprises of sensor, micro-controller and RF transceiver and is often driven by a battery or energy harvesting system with tiny operating systems (see Figure 4). The energy harvesting technology is applied by utilising external energy sources and harvesting energy from a variety of ambient energy sources and converts it into electrical energy to recharge the batteries (Zhang et al., 2017). Balancing energy consumption in the network nodes is another techniqus to extending the WSN life by searching an optimal network structure (Elhoseny et al., 2015; Yuan et al., 2017). The optimal structure coverage the sensed reigon using k-coverage using GA-based model maximise the network lifetime (Elhoseny et al., 2017). The WSN standards are designed to take into account the scarce resources of nodes. Two standard technologies are available for WSNs: ZigBee and Bluetooth. The ZigbBee is most suitable for remote sensing and space applications due to its higher battery life, higher number of nodes and network flexibility which allowing different topologies through multi-hop communication (Qingshan et al., 2004). The space sensor network is based on low cast small or pico satellite technologies with fundamental payload that provide new distributed sensing capabilities. This satellite node stays in 
space undergoing complex orbital dynamics and required large numbers of satellites forming a constellation (Barnhart, 2008). These satellites are linked via ground relays and systems with inter-satellite communications based on standard wireless protocols (Vladimirova et al., 2008).

Figure 2 Space sensor networks architecture (see online version for colours)

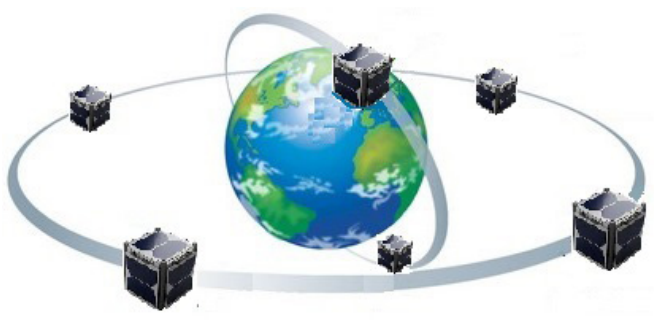

Figure 3 WSNs applications in remote sensing and space domains (see online version for colours)

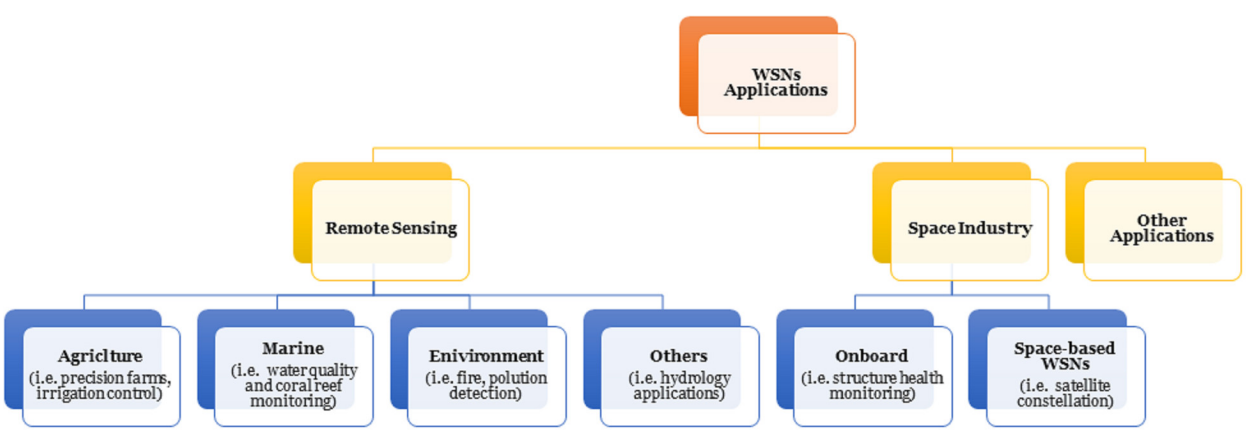

Figure 4 Wireless sensor node functional blockdiagram (see online version for colours)

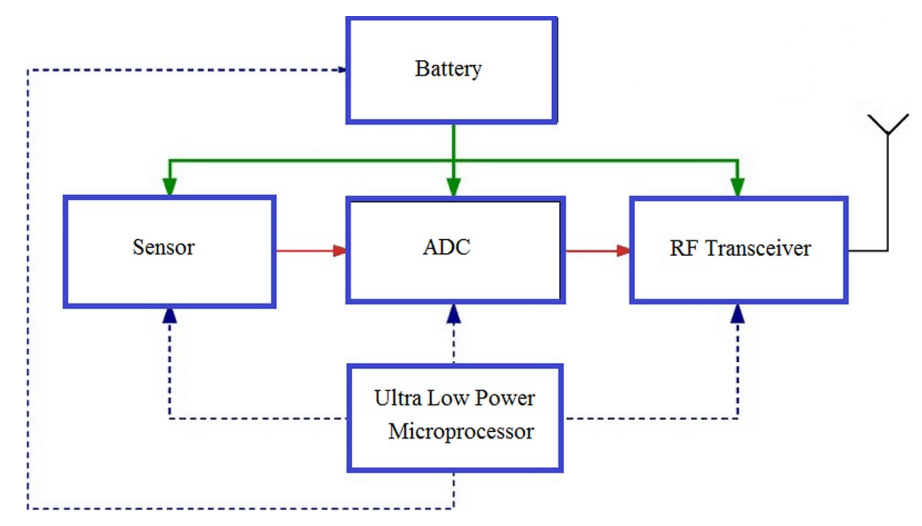

This paper, presented a state-of-art survey shows the recent developments and applications in the field of sensor networks within the domains of remote sensing and 
space applications as shown in Figure 3. The key contribution of this paper is presenting the recent survey for the current sensor networks applications from the perspectives of remote sensing and space industry. Moreover, it emphasise on the importance of sensor networks in space industry and their challenges. Our main aim is to emphasize and boost the use of sensor networks in remote sensing, monitoring and space industry in Egypt. In the remainder of this paper, Section 2 presents the application of WSNs in agricultures domains. In Section 3 and Section 4, the application of WSNs in marines and environment monitoring are presented. In Section 5 the applications of WSNs in space industry are demonstrated with their challenges. Finally, Section 6 concludes the paper.

\section{Agriculture applications}

Agriculture is one of the most important filed where WSNs innovation and technology are used for improving production. The WSNs deliver a new approach of gathering information from the environment and save the wasted and minimise the use of resources and produce high yields. Plant conditions are usually committed to faraway weather stations which cannot provide accurate and local measurements of the fundamental parameters in each zone of the field. Also, agronomic models, based on these monitored data, cannot provide reliable information. On the other side, agriculture needs detailed monitoring in order to obtain real time feedback between plants, local climate conditions and man's decisions. Cugati et al. (2003) developed an automated fertiliser applicator for tree crops. Recently, Di Palma et al. (2010) developed a system comprised of a self-organising WSN endowed with sensing capabilities, a GPRS gateway which gathers data and provides a TCP-IP based connection toward a remote server and a web application which manages information and makes the final user capable of monitoring and interacting with the instrumented environment. Abd El-kader and El-Basioni (2013) presented and discussed the use of WSNs in Egypt and the benefits to use WSN in potato farming, the process will automate the scheduling, fertilising and planting of potato. This will improve the production and storing process to avoid disease and harmful fungi especially when old land is used. Coates et al. (2012) describe sensor network based precision irrigation and problems and challenges of agricultural water management and how to improve water use effectiveness. WSNs are used in managing crop irrigation from open canals using water pumps in delta of Egypt (Hassan, 2013). Qu et al. (2014) developed a WSN system to take automatic crop leaf area index (LAI) measurements that are suitable for validating the remotely sensed images. A remote sensing and control irrigation system using distributed WSN aiming for variable rate irrigation, real time in field sensing, controlling of a site specific precision linear move irrigation system to maximise the productivity with minimal use of water was developed by Kim et al. (2008). Recently, fuzzy-based irrigation controller for tomato is implemented using WSN (Mohandas et al., 2017). WSNs can collect multi-sensing data including local climate parameters and pest populations to model agro-ecosystems with higher scalability and flexibility (Chen et al., 2013). The first efforts of using sensor networks for pests detection in the Sugarcane farms based on the uses of an acoustic device sensor which monitors the noise level of the pests and gives an indication to the farmer through an alarm when the noise crosses a threshold (Mankin et al., 2011; Srivastava et al., 2013). Other studies (Ruiz-Garcia et al., 
2009; Chaudhary et al., 2011) conducted show that WSN technologies can be used in the area of agriculture as well.

\section{Marine applications}

WSNs have recently been considered as alternative solutions for monitoring marine environments. Where various kinds of sensors are used to monitor and measure different physical and chemical parameters such as water temperature, pressure, wind direction, wind speed, salinity, turbidity, $\mathrm{pH}$, oxygen density and chlorophyll levels (Xu et al., 2014). These systems are used for different water environments (i.e., surface, underground) and has a broad number of application areas such as:

1 water quality monitoring (Alkandari et al., 2012)

2 ocean sensing and monitoring (Perez et al., 2011)

3 coral reef monitoring (Bromage et al., 2007)

4 marine fish farm monitoring (Sutar and Patil, 2013).

These application areas require different WSN system architectures, communication technologies and sensing technologies (Xu et al., 2014). The WSNs has facing many challenges for marine environment monitoring including oceanographic sensors protection, advanced buoy design, movement reconfiguring where the sea water creates environmental conditions which negatively influence the network parameters, such as breaking up the buoy nodes and sometimes the WSN may need reconfiguring and system stability and reliability (Xu et al., 2014). Currently, the UAV is used to monitoring marine environments by collecting data from drifting buoysas primary environmental sensors, as a data sink and dynamic network router (Trasvina-Moreno et al., 2017). Monitoring the tempo-spatial variation patterns of water-level is another application which have their effect on flood control and management (Weng et al., 2017).

\section{Environmental monitoring applications}

WSNs become an important issue in environmental monitoring such as detect rainfall, air pollution and weather conditions. WSNs can be used to detect and forecast forest fire quicker than the traditional satellite-based detection approach. WSN based fire surveillance systems was designed and implemented. An example WSNs system developed for forest fire detection based on fire weather index (FWI) system (Hefeeda and Bagheri, 2007). WSNs used in forest fire detection and monitoring based on National Fire Danger Rating System, temperature and humidity (Aslan, 2010). WSN used in measuring temperature, humidity and detect smoke (Son et al., 2006). Another successful application for WSNs is to detect the marine pollution resulted from the oil spills. Denkilkian et al. (2009) implement a WSN system for continuous and real-time thickness measurement and localisation of oil based on the difference in the absorbance spectral signatures and electric conductivity properties of oil and water. The system overcomes the traditional methods of remote sensing that are based on synthetic aperture radar (SAR) and laser fluorosensor techniques, which suffers from many drawbacks, 
such as delayed response, high cost and dependence on weather, lighting, temperature and sea conditions (Barbosa et al., 2008; Denkilkian et al., 2009). Harchi et al. (2012) proposed an information system for the oil slicks surveillance using a WSN. As shown in Figure 5 once deployed on the oil slicks, these wireless sensors self-organise into distributed sub-networks to collect data and transmit them to a data processing station.

Figure 5 WSN system for oil spill monitoring (see online version for colours)

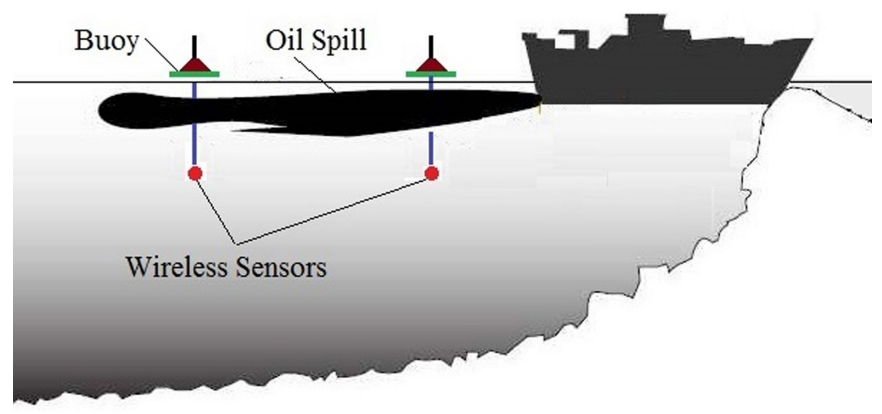

\section{Applications of sensor networks in space}

Wireless sensors networks have many applications within the space industry that are proposed such as:

1 Onboard sensor network

2 Space-based sensor networks (Sun et al., 2010; Xie et al., 2014).

\subsection{Onboard WSNs applications}

The onboard WSNs have been successfully applied in many aerospace engineering applications such as structural health monitoring (SHM). The aim of SHM is to monitor aircrafts and spacecrafts using embedded or attached sensors and to utilise the data in order to ensure the structural integrity of the aircraft or spacecraft for defects (Staszewski et al., 2004). Sensors are used to collecting data about the behaviour of the rocket/space craft when flying, identifying the anomalies in operation (Trojaolaa, 2011). The traditional systems are based on wired connections and, therefore, they are complex and difficult to route. The power cable and electrical signal cable should be physically separated to avoid electrical interference (Lappas et al., 2006). Also, harsh environmental conditions impose physical restrictions on the use of a wire harness. However, cabling implies high installation and maintenance costs. Moreover, cables are subjected to wear or breakage which cause the major aircraft accidents and delays of space vehicle launches. Replacing the physical cabling by wireless connections also offers significant benefits as regards flexibility, interoperability, mass reduction and improved robustness. These constraints are pushing the development of wireless technology for all aerospace applications which present a better option when retrofitting sensors onto existing aircraft or spacecraft. The use of WSN also enables reduction in direct costs, maintenance cost and the costs of performing safety re-certification. 
The WSNs consistently reduce the installation, maintenance costs and thus improving safety and reliability (Rama and Rohit, 2011; Vujic, 2015). Chinese researcher have applied a WSNs for aircraft strength testing (AST) and its evaluation on a real aircraft specimen ( $\mathrm{Wu}$ et al., 2009). As shown in Figure 6, the AST systems consists of a number of sensor nodes, several cluster head nodes and additional optional wireless router nodes that help with data aggregation and transmission via wireless multi-hop. Other WSNs are being developed for monitoring the health of aircraft engines on commercial and military aircraft as well as on NASA spacecraft (Nickerson and Lally, 2001; Bai et al., 2004). Watters et al. (2002) have been designed wireless system to monitor the temperature of the space shuttle's thermal protection systems. The system utilises radio frequency identification (RFID) technology to determine whether a temperature threshold has been exceeded. For satellite, as shown in Figure 7, a simplified illustration shows the key parts in order to ensure the safety of the satellite system, the candidate wireless sensor nodes are relative-low-data-rate housekeeping sensors (or satellite health and status data) (i.e., temperature, pressure and vibration sensors) and relative-high-data-rate ADCS sensors (i.e., sun sensor, star tracker). The WiSe-Net is an example of a COTS based narrow-band RF wireless sensor network inside the ISS that applied WSN technology in space (Beestermoller et al., 2015).

Figure 6 WSN-based system for AST (see online version for colours)

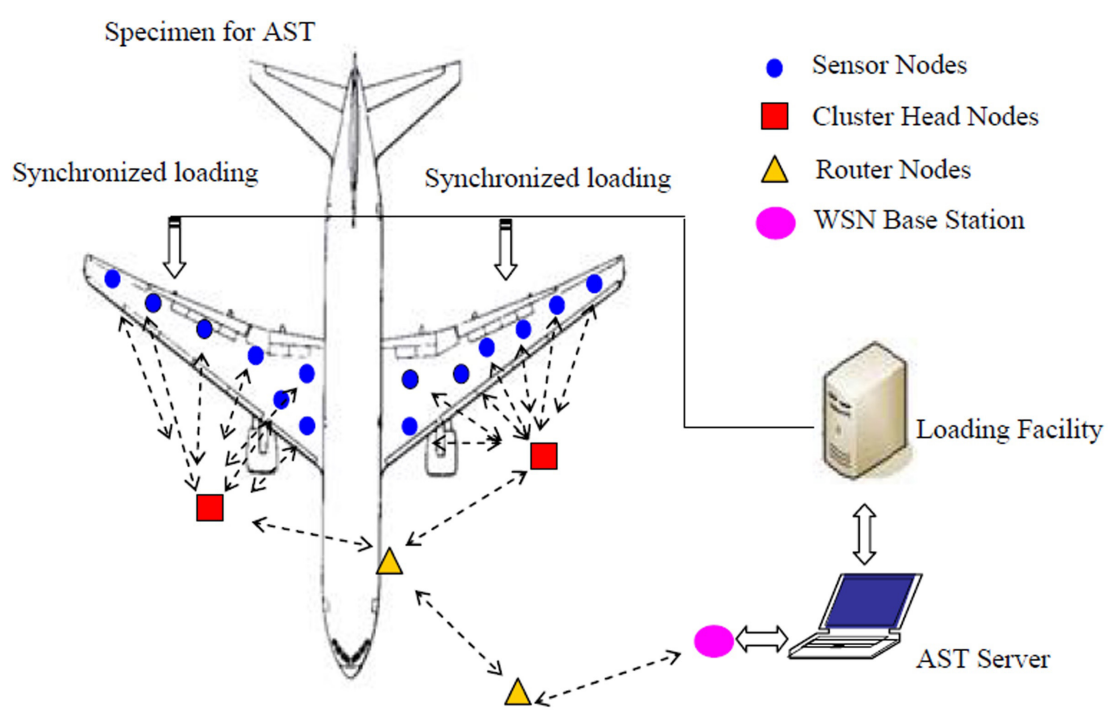

Source: Wu et al. (2009)

\subsection{Space-based WSNs applications}

An advances technologies of small satellite enabling the space sensor network applications where the satellite sensor network consists of multiple satellites that deployed by a signal launch vehicle and enable remote observation of real-time multi-point phenomena. For example, NASA's Earth science constellation is 
coordinating a number of different satellites into a train-like arrangement to provide near simultaneous observations of the same area of the earth as a first step of satellite sensor network (Sun et al., 2010; Xie et al., 2014). The wireless communication between two nodes in the network will rely on inter-satellite link or intra-satellite link, whose establishment and stability are affected by the satellite orbit and attitude, antenna configuration, link range, mobility or the layout of spacecraft. Inter-satellite links enable the satellites to exchange information and share resources while reducing the traffic load to ground. Intra-satellite links wirelessly connect a number of onboard sensors or actuators to reduce wired harnesses and connectors inside a spacecraft. Such networks are more similar to the terrestrial WSNs because the nodes in the networks have relatively fixed position and short link range. The network design should furthermore consider the layout of the satellites, minimum mass, power consumption, redundancy and data fusion at node and network level which is significantly complex (Jallad, 2008; Rodrigues et al., 2014). Autonomous formation flying is a good demonstration platform for satellite sensor network. For example, the PRISMA mission is the first demonstration of autonomous formation flying with S-band RF-based meteorology at centimeter-level ranging accuracy (Lestarquit et al., 2006). Using numerous cheaper micro-, nano- or even pico-satellites in a cluster/swarm for multipoint exploration is a challenging but very attractive idea. Cluster/swarm can get a large area coverage and unprecedented high resolution can go to places that are difficult to reach or too dangerous for standard spacecraft (Verhoeven et al., 2009). The need for a cluster of satellites is to ensure data can be recorded from multiple payloads at a specific time at various non-specific local locations. A good example of cluster/swarm in space are OLFAR mission which will operate as a coherent array of approximately 50 CubeSats within a $100 \mathrm{~km}$ virtual aperture (Budianu et al., 2011).

Figure 7 Onboard WSN to replace wiring harnesses and connectors (see online version for colours)

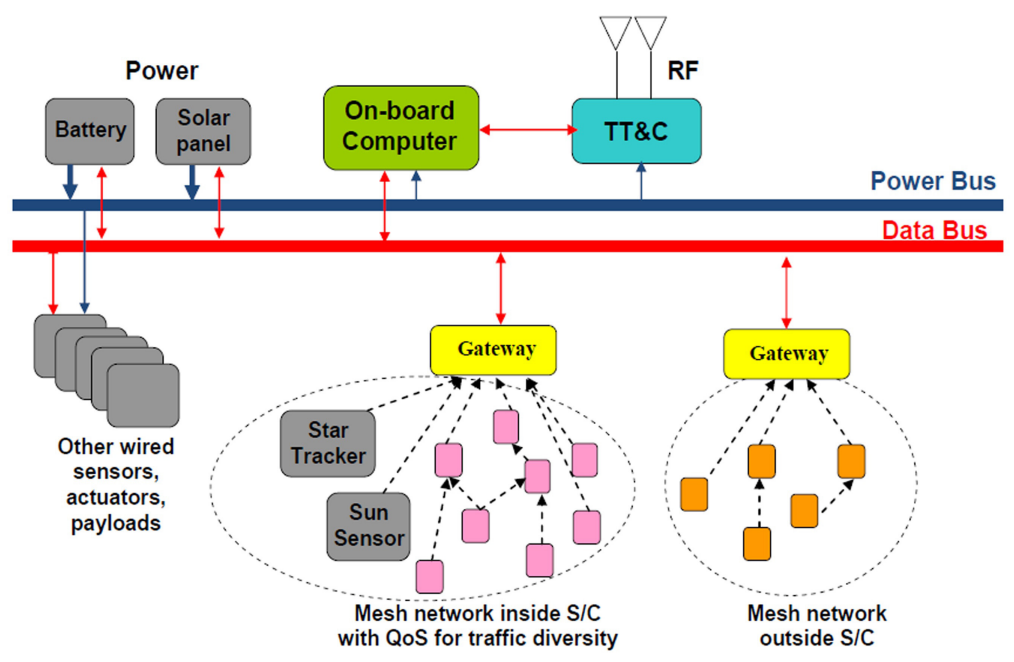

Source: Sun et al. (2010) 


\subsection{Challenges of sensor networks in space applications}

The miniaturisation of satellites is the key factor of space-based WSNs in order to reduce the cost of deployment and on-board communication systems (Sebestyen et al., 2014). The implementation of space-based WSNs facing many challenges because the specific characteristics of space environments which are very harsh with temperature extremes from cryogenic to very high temperatures and pressure from vacuum to very high pressures. Shock and vibration levels during launch are often high enough to cause component failures. Another issue will be the certification of WSNs for flight. This includes the allocation of a frequency spectrum for wireless sensing, along with the determination RF power levels and FAA acceptance for aircraft use. The electromagnetic compatibility (EMC) and interference poses a problem for WSNs, an insensitive technology such as optical communication could be used to overcome this problem such as infrared (IR) based communication system (Beestermoller et al., 2015). The electronics must be designed to be tolerant if not hardened against higher levels of ionising radiation for space applications (Vladimirova et al., 2007, 2010; Xie et al., 2014). Waste heat from electronics is difficult to dispose of in space when operating in vacuum conditions which eliminate all convection, leaving only conductive or thermal radiation methods for heat removal. Reducing the cost associated with adjusting wireless sensors on aircraft and spacecraft is always a challenge. The WSNs for aerospace applications must have small volume and mass due to the high costs associated with launching items to space (Wilson and Atkinson, 2008). Finally, there are some limitations concerning the photovoltaic utilisation specially in CubeSat, the energy harvesting sensors play a big role here by extracting power from the surrounding space environment. There is many techniques to harvest various energies in the space environment, selection of which should be suitable is application and environment dependent. Actually, the energy harvesting technologies are still not mature and the output power and energy conversion efficiency are low. Finally, there is a great need for standardisation of wireless standards and protocols for future space sensor networks as well, to ensure interoperability not only for the existing frameworks but also for the future ones (Wagner, 2010).

\section{Conclusions}

Utilising WSNs in remote monitor and control applications can bring lots of benefit for hardly investigated environments. The WSNs have been successfully implemented and tested in real-time remote sensing applications. The application of WSNs in space industry is still in its early stages and most WSN-based systems are purely experimental. Although many challenges still exist in the space, in spite of the shortcoming, it has been gaining significant attention among researchers and technologists due to its promising future. The implementation of WSNs in space faces many challenges which must be investigated before its usage in space domain. Also, there are many topics such as electromagnetic interference, ionising radiation, thermal dissipation, vibration, shock and harsh environments must be considered and examined. However, integrating WSNs in space industry overs many advantages such as: 
1 elimination of cable harnessing which is prone to human errors

2 reduce spacecraft configuration complexity, mass and volume.

\section{References}

Abd El-kader, S. and El-Basioni, B. (2013) 'Precision farming solution in Egypt using the wireless sensor network technology', Egyptian Informatics Journal, Vol. 14, No. 3, pp.221-233.

Akyildiz, I., Su, W., Sankarasubramaniam, Y. and Cayirci, E. (2002) 'Wireless sensor networks: a survey', IEEE Communications Magazine, Vol. 38, No. 4, pp.393-422.

Alkandari, A., Alnasheet, M., Alabduljader, Y. and Moein, S. (2012) 'Water monitoring system using wireless sensor network (WSN): case study of kuwait beaches', Proceedings of the 2nd International Conference on Digital information Processing and Communications, pp.10-15.

Aslan, Y. (2010) A Framework for the Use of Wireless Sensor Networks in the Forest Fire Detection and Monitoring, $\mathrm{PhD}$ thesis, The Institute of Engineering and Science, Bilkent University.

Bai, H., Atiquzzaman, M. and Lilja, D. (2004) 'Wireless sensor network for aircraft health monitoring', Proceedings of the 1st International Conference on Broadband Networks, pp.748-750.

Barbosa, P., White, N. and Harris, N. (2008) 'Wireless sensor network for localized maritime monitoring', 22nd International Conference on Advanced information Networking and Applications, Vol. 12, pp.681-686.

Barnhart, D., Vladimirova, T. and Sweeting, M. (2007) 'Very small satellite design for distributed space missions', AIAA Journal of Spacecraft and Rockets, Vol. 44, No. 6, pp.1294-1306.

Barnhart, D. (2008) Very Small Satellite Design for Space Sensor Networks, PhD thesis, University of Surrey.

Beestermoller, H., Sebald, J., Sinnreich, M., Borchers, H., Schneider, M., Luttmann, H. and Schmid, V. (2015) 'Wireless-sensor networks in space technology demonstration on ISS', Dresdner Sensor Symposium, pp.98-102.

Bromage, M., Obraczka, K. and Potts, D. (2007) 'SEA-LABS: A wireless sensor network for sustained monitoring of coral reefs', Proceedings of the 6th International IFIP-TC6 Conference on Ad Hoc and Sensor Networks, Wireless Networks, Next Generation Internet, pp.1132-1135.

Budianu, A., Rajan, R., Engelen, S., Meijerink, A., Verhoeven, C. and Budianu, M. (2011) 'OLFAR: adaptive topology for satellite swarms', Proceedings of 60th International Astronautical Congress, pp.1-9.

Chaudhary, D., Nayse, S. and Waghmare, L. (2011) 'Application of wireless sensor networks for greenhouse parameter control in precision agriculture', International Journal of Wireless and Mobile Networks, Vol. 3, No. 1, pp.140-149.

Chen, C., Liao, M. and Jiang, J. (2013) 'Adaptive classification of special events in agroecological monitoring systems for pest management', in Mukhopadhyay, S. and Jiang, J. (Eds.): Wireless Sensor Networks and Ecological Monitoring. Smart Sensors, Measurement and Instrumentation, Vol. 3, pp.269-296, Springer.

Coates, R., Delwiche, M., Broad, A., Holler, M., Evans, R., Oki, L. and Dodge, L. (2012) 'Wireless sensor network for precision irrigation control in horticultural crops', International Conference of Agricultural Engineering, pp.1-8. 
Cugati, S., Miller, W. and Schueller, J. (2003) 'Automation concepts for the variable rate fertilizer applicator for tree farming', Proceedings of 4th European Conference in Precision Agriculture, Germany, pp.14-19.

Denkilkian, H., Koulakezian, A., Ohannessian, R., Chalfoun, M., Joujou, M., Chehab, A. and Elhajj, I. (2009) 'Wireless sensor for continuous real-time oil spill thickness and location measurement', IEEE Transaction on Instrumentation and Measurement, Vol. 58, No. 12, pp.4001-4011.

Di Palma, D., Bencini, L., Collodi, G. and Manes, A. (2010) 'Distributed monitoring systems for agriculture based on wireless sensor network technology', International Journal on Advances in Networks and Services, Vol. 3, No. 1, pp.18-28.

Elhoseny, M., Yuan, X., Zhou, H. and Yu, Z. (2015) 'Balancing energy consumption in heterogeneous wireless sensor networks using genetic algorithm', IEEE Communications Letters, Vol. 19, No. 12, pp.2194-2197.

Elhoseny, M., Tharwat, A., Farouk, A. and Hassanien, A. (2017) 'K-coverage model based on genetic algorithm to extend WSN lifetime', IEEE Sensors Letters, Vol. 1, No. 4, pp.1-5.

Harchi, S., Georges, J. and Divoux, T. (2012) 'WSN dynamic clustering for oil slicks monitoring', 3rd International Conference on Wireless Communications in Unusual and Conned Areas, pp.1-6.

Hassan, A. (2013) 'Web-based irrigation management for open canals using wireless sensor networks', IEEE Conference on Wireless Sensors, pp.102-107.

Hefeeda, M. and Bagheri, M. (2007) 'Wireless sensor networks for early detection of forest fires', Proceedings of the IEEE International Conference on Mobile Adhoc and Sensor Systems (MASS'07).

Hill, J. and Culler, D. (2002) 'Mica: a wireless platform for deeply embedded networks', Micro, IEEE, Vol. 22, No. 6, pp.12-24.

Iyer, A., Kulkarni, S., Mhatre, V. and Rosenberg, C. (2008) 'A taxonomy-based approach to design of large-scale sensor networks', in Li, Y., Thai, M.T., Wu, W. (Eds.): Wireless Sensor Networks and Applications. Signals and Communication Technolog, Chapter 1, pp.3-33, Springer.

Jallad, A. (2008) Distributed Computing in Space-based Wireless Sensor Networks, PhD thesis, University of Surrey.

Kim, Y., Evans, R. and Iversen, W. (2008) 'Remote sensing and control of an irrigation system using a distributed wireless sensor network', IEEE Transactions on Instrumentation and Measurement, Vol. 57, No. 7, pp.1379-1387.

Lappas, V., Prassinos, G., Baker, A. and Magnuss, R. (2006) 'Wireless sensor motes for small satellite applications', IEEE Antennas and Propagation Magazine, Vol. 48, No. 5. pp.175-179.

Lestarquit, L., Harr, J., Grelier, T., Peragin, E., Wilhelm, N., Mehlen, C. and Peyrotte, C. (2006) 'Autonomous formation flying RF sensor development for the PRISMA mission', 19th International Technical Meeting for the Satellite Division.

Li, X., Liu, Q., Yang, R., Wen, J., Zhang, J., Cai, E. and Zhang, H. (2016) 'The combination of ground-sensing network and satellite remote sensing in Huailai county', IEEE Sensors Journal, Vol. 16, No. 10, pp.3819-3826.

Mankin, R., Hagstrum, D., Smith, M., Roda, A. and Kairo, M. (2011) 'Perspective and promise: a century of insect acoustic detection and monitoring', American Entomologist, Vol. 57, No. 1, pp.30-44.

Mazayev, A., Correia, N. and Schutz G. (2016) 'Data gathering in wireless sensor networks using unmanned aerial vehicles', International Journal of Wireless Information Networks, Vol. 23, No. 4, pp.297-309. 
Mohandas, P., Sangaiah, A., Abraham, A. and Anni, J. (2017) 'An automated irrigation system based on a low-cost microcontroller for tomato production in South India', Computational Intelligence in Wireless Sensor Networks Recent Advances and Future Challenges, pp.49-71.

Mollenhauer, H., Pflug, B., Lausch, A., Borg, E., Mollenhauer, O., Dietrich, P. and Bumberger, J. (2017) 'Mobile wireless sensor networks for ground truthing multispectral remotely sensed data', Possibilities and Challenges in the Context of Current and Future Earth Observation Data, UFZ Leipzig.

Nickerson, B. and Lally, R. (2011) 'Development of a smart wireless networkable sensor for aircraft engine health management', Proceedings of the IEEE Aerospace Conference, pp.3255-3262.

Perez, C., Jimenez, M., Soto, F., Torres, R., López, J. and Iborra, A. (2011) 'A system for monitoring marine environments based on wireless sensor networks', Proceedings of the IEEE Conference on OCEANS, pp.1-6.

Qingshan, S., Ying, L., Gareth, D. and Brown, D. (2004) 'Wireless intelligent sensor networks for refrigerated vehicle', IEEE 6th Symposium on Emerging Technologies Mobile and Wireless Communication, Shanghai, China, pp.525-528.

Qu, Y., Zhu, Y., Han, W., Wang, J. and Mingguo, M. (2014) 'Crop leaf area index observations with a wireless sensor network and its potential for validating remote sensing products', IEEE Journal of Selected Topics in Applied Earth Observations and Remote Sensing, Vol. 7, No. 2, pp.431-444.

Rama, K. and Rohit, K. (2011) 'Application of wireless sensor networks to aircraft control and health management systems', Journal of Control Theory Applications, Vol. 9, No. 1, pp.28-33.

Rodrigues, B., Tekever, A., Alvarez, F., Cabas, R., Oddi, G., Liberati, F., Vladimirova T., Zhai, X., Jing, H. and Crosnier, M. (2014) 'Space wireless sensor networks for planetary exploration: node and network architectures', Proceedings of NASA/ESA Conference on Adaptive Hardware and Systems (AHS), pp.180-187.

Ruiz-Garcia, L., Lunadei, L., Barreiro, P. and Robla, J. (2009) 'A review of wireless sensor technologies and applications in agriculture and food industry: state of the art and current trends', Sensors, Vol. 9, No. 6, pp.4728-4750.

Sebestyen, G., Fujikawa, S., Galassi, N. and Chuchra, A. (2014) Low Earth Orbit Satellite Design, Springer, ISBN: 978-3-319-68314-0.

Son, B., Her, Y. and Kim, J. (2006) 'A design and implementation of forest-fires surveillance system based on wireless sensor networks for South Korea mountains', International Journal of Computer Science and Network Security, Vol. 6, No. 9B, pp.124-130.

Srivastava, N., Chopra, G., Jain, P. and Khatter, B. (2013) 'Pest monitor and control system using wireless sensor network with special reference to acoustic device wireless sensor', International Conference on Electrical and Electronics Engineering, Vol. 3, No. 2, pp.40-46.

Staszewski, W., Boller, C. and Tomlinson, G. (2004) Health Monitoring of Aerospace Structures Smart Sensor Technologies and Signal Processing, John Wiley \& Sons, Ltd., ISBN: 9780470843406.

Sun, R., Guo, J. and Gill, E. (2010) 'Opportunities and challenges of wireless sensor networks in space', 61st International Astronautical Congress, IAF, pp.1-12.

Sutar, K. and Patil, R. (2013) 'Wireless sensor network system to monitor the fish farm', International Journal of Engineering Research and Applications, Vol. 3, No. 5, pp.194-197.

Trasvina-Moreno, C., Blasco, R., Marco, A., Casas, R. and Trasvina-Castro, A. (2017) 'Unmanned aerial vehicle based wireless sensor network for marine-coastal environment monitoring', Sensors, Vol. 17, No. 3, pp.1-22. 
Trojaolaa, M. (2011) 'Sensors and systems in space: Ariane 5', Sesnors and Actuators A, Vols. 37-38, pp.233-238.

Verhoeven, C., Budianu, M., Monna, C. and Rotteveel, J. (2009) 'On the origin of satellite swarms', Proceedings of 60th International Astronautical Congress, pp.1-5.

Vladimirova, T. et al. (2007) 'Characterising wireless sensor motes for space applications', Proceedings of 2nd NASA/ESA Conference on Adaptive Hardware and Systems, pp.43-50.

Vladimirova, T., Wu., X. and Barnhart, D.(2007) 'Development of a satellite sensor network for future space missions', IEEE Aerospace Conference, pp.1-10.

Vladimirova, T., Bridges, C., Paul, J. and Malik, S. (2010) 'Space-based wireless sensor networks: design issues', IEEE Aerospace Conference, pp.1-14.

Vujic, D. (2015) 'Wireless sensor networks applications in aircraft structural health monitoring', Journal of Applied Engineering Science, Vol. 13, No. 2, pp.79-86.

Wagner, R.S. (2010) 'Standards-based wireless sensor networking protocols for spaceflight applications', IEEE Aerospace Conference, pp.1-7.

Watters, D., Jayaweera, P., Bahr, A., Huestis, D. (2002) 'Design and performance of wireless sensors for structural health monitoring', Proceedings of the Quantitative Nondestructive Evaluation Conference, pp.969-976.

Weng, S., Zhaib, D., Yanga, X. and Hua, X. (2017) 'A ZigBee wireless networking for remote sensing applications in hydrological monitoring system', Proc. SPIE 10322 th International Conference on Electronics and Information Engineering.

Wilson, W. and Atkinson, G. (2008) 'Wireless sensing opportunities for aerospace applications', Sensors \& Transducers Journal, Vol. 94, No. 7, pp.83-90.

Wu, J., Yuan, S., Zhou, G., Ji, S., Wang, Z. and Wang, Y. (2009) 'Design and evaluation of a wireless sensor network based aircraft strength testing system', Sensors, Vol. 9, No. 6, pp.4195-4210.

Xie, S., Lee, G., Low, K. and Gunawan, E. (2014) 'Wireless sensor network for satellite applications: a survey and case study', Unmanned Systems, Vol. 2, No. 3, pp.261-277.

$\mathrm{Xu}, \mathrm{G}$., Shen, W. and Wang, X. (2014) 'Applications of wireless sensor networks in marine environment monitoring: a survey, Sensors, Vol. 14, No. 9, pp.16932-16954.

Yuan, X., Elhoseny, M., El-Minir, H. and Riad A. (2017) 'A genetic algorithm-based, dynamic clustering method towards improved WSN longevity', Journal of Network and Systems Management, Vol. 25, No. 1, pp.21-64.

Zhang, D., Chen, Z., Zhou, H. and Shen, X. (2017) Resource Management for Energy and Spectrum Harvesting Sensor Networks, Springer, ISBN: 978-3-319-53770-2. 